\title{
Syringomyelia, neuropathic arthropathy and rheumatoid arthritis as diagnostic dilemmas in two different cases: confounding factor and true coexistence
}

\author{
Fabricio de Souza Neves • Deborah Pereira Gonçalves • \\ Célio Roberto Gonçalves
}

Published online: 7 November 2006

(C) Clinical Rheumatology 2006

The online version of the original article can be found at: http://dx.doi. org/10.1007/s10067-005-0102-4.

F. S. Neves • D. P. Gonçalves • C. R. Gonçalves

Division of Rheumatology, University of Sao Paolo,

Sao Paulo, Brazil

F. S. Neves $(\bowtie)$

Rua Dr., Diogo de Farias 1104, Ap 92, Vila Clementino,

CEP 04037003 Sao Paulo, Brazil

e-mail: nevesfab@bol.com.br
In the XML version of the online publication the family names of all authors were incorrectly given:

- the name of Fabricio de Souza Neves as de Sausa Neves. The correct family name is Neves;

- the name of Deborah Pereira Gonçalves as Pereira Gonçalves. The correct family name is Gonçalves;

- the name of Célio Roberto Gonçalves as Roberto. The correct family name is Gonçalves. 